\title{
Mussel Inspired Preparation of Functional Silica Nanocomposites for Environmental Adsorption Applications
}

Qiang Huang ${ }^{\mathrm{a}, ~ \#}$, Meiying Liu ${ }^{\mathrm{a}, \#}$, Junyu Chen ${ }^{\mathrm{a}}, \mathrm{Ke} \mathrm{Wang}^{\mathrm{b}}$, Dazhuang Xu ${ }^{\mathrm{a}}$, Fengjie Deng ${ }^{\mathrm{a}}$, Hongye Huang ${ }^{\mathrm{a}}$, Xiaoyong Zhang ${ }^{\mathrm{a},{ }^{*}}$, Yen $\mathrm{Wei}^{\mathrm{b}, *}$

a Department of Chemistry, Nanchang University, 999 Xuefu Avenue, Nanchang 330031, China

b Department of Chemistry and the Tsinghua Center for Frontier Polymer Research, Tsinghua University, Beijing, 100084, P. R. China.

\# These authors contributed equally to this work 


\section{Abstract}

Surface modification of nanomaterials with polymers is an effective route to render new functions and improve the performance of the final nanocomposites. Here, a facile method was developed to fabricate polyacrylic acid (PAA)-grafted monodisperse $\mathrm{SiO}_{2}$ nanoparticles $\left(\mathrm{SiO}_{2}\right.$-PDA-PAA) through a combination of mussel inspired chemistry and Michael addition reaction. To obtain the products, the $\mathrm{SiO}_{2}$ nanoparticles were first coated with polydopamine (PDA) through self-polymerization of dopamine under rather mild conditions. The PDA thin films can then be further conjugated with amino-terminated PAA, which was synthesized by chain transfer free radical polymerization using cysteamine hydrochloride as a chain transfer agent and acrylic acid as a monomer. The $\mathrm{SiO}_{2}$-PDA-PAA nanocomposites were characterized via transmission electron microscopy, Fourier transform infrared spectroscopy, thermal gravimetric analysis, and $\mathrm{X}$-ray photoelectron spectroscopy. The effect of contact time, solution $\mathrm{pH}$, temperature and methylene blue (MB) concentration on the removal of $\mathrm{MB}$ were investigated. The results demonstrated that $\mathrm{SiO}_{2}$-PDA-PAA showed significant improvement in adsorption efficiency towards MB. The kinetics and isotherm studies showed that pseudo-second-order and Langmuir isotherm models were well fitted the experimental data. The values of thermodynamics parameters such as entropy change $\left(\Delta S^{0}\right)$, enthalpy change $\left(\Delta H^{0}\right)$ and Gibbs free energy $\left(\Delta G^{0}\right)$ were calculated based on the Van't Hoff equation. The negative values of thermodynamic parameters indicated that the adsorption of MB was a feasible, spontaneous and exothermic process. In summary, we developed a facile method to fabricate $\mathrm{SiO}_{2}$-based polymer nanocomposites, which showed obviously enhanced adsorption capability towards MB.

Key words: Mussel inspiration; Michael addition reaction; $\mathrm{SiO}_{2}$ nanocomposites; Methylene blue; Self-polymerization of dopamine. 


\section{Introduction}

$\mathrm{SiO}_{2}$ nanoparticles are one of the most important inorganic nonmetallic nanomaterials and possess many unique properties including high thermo-stability, excellent optical and electrical properties, and good mechanical properties.[1] These remarkable features mean that $\mathrm{SiO}_{2}$ nanomaterials can be used as desiccants, catalyst supports[2], separation agents[3], drug carriers[4, 5] and adsorbents[6-11] as well as a tool to remove pollutants. However, unmodified $\mathrm{SiO}_{2}$ nanoparticles lack functional groups, which results in limited adsorption capability for these $\mathrm{SiO}_{2}$ nanoparticles. Therefore, several surface modification methods such as layer-by-layer assembly and grafting copolymerization have been reported to overcome this issue.[12-17] However, most of these methods have some deficiencies and limitations including a challenging experimental procedure, complex and expensive instruments, long reaction time and stringent reaction conditions. Hence, it is highly desirable to explore a facile and effective strategy for surface modification of $\mathrm{SiO}_{2}$ nanoparticles.

Mussel-inspired modification is a novel strategy for surface modification and was first reported by Waite et al. in the 1980s.[18] Afterwards, Lee at al demonstrated that dopamine (DA) could form polydopamine (PDA) films onto a wide range of inorganic and organic materials through self-polymerization in alkaline aqueous solution.[19-24] Thus, mussel-inspired chemistry has been regarded as a new route for surface modification for various materials and surfaces. For example, Fei et al. reported a method to synthesize PDA-coated carbon nanotubes with tunable thickness by adjusting the polymerization time.[25]

Sung et al. developed a one-step, solution-based surface chemical method to modify super hydrophobic surfaces via a mussel-inspired surface coating.[26] Yang et al. demonstrated a method to prepare a layer of protective shell on the surface of yeast cells combined with covalent conjugate and self polymerization of DA.[27] We reported the preparation of carbon nanotubes, graphene oxides and $\mathrm{SiO}_{2}$ nanoparticle-based nanocomposites through mussel-inspired chemistry.[28-37] Because of the universal and strong adhesion of PDA towards various substrates, mussel-inspired chemistry has been extensively investigated for different applications.[38-40] However, the surface modification of $\mathrm{SiO}_{2}$ nanoparticles with polymers through mussel-inspired chemistry is rarely reported. The utilization of these polymer-modified $\mathrm{SiO}_{2}$ nanoparticles for removal of environmental pollutants has not yet been reported.

Herein, we report a facile method for the surface modification of $\mathrm{SiO}_{2}$ nanoparticles via mussel-inspired chemistry and a Michael addition reaction (Scheme 1). The $\mathrm{SiO}_{2}$ nanoparticles were prepared according to a slightly modified Stöber method. The $\mathrm{SiO}_{2}$ nanoparticles were coated on PDA films via self-polymerization of DA. The PDA films are a platform for the secondary reactions. Amino-terminated PAA were synthesized from free radical polymerization and contained many carboxyl functional groups. This was immobilized on the surfaces of the $\mathrm{SiO}_{2}$ nanoparticles via a Michael addition reaction. The successful preparation of functionalized $\mathrm{SiO}_{2}$ nanocomposites was confirmed by transmission electron microscopy (TEM), Fourier transform infrared (FT-IR) spectroscopy, thermal gravimetric analysis (TGA), and X-ray photoelectron spectroscopy (XPS). Batch experiments were carried out to study the adsorption performance of functionalized $\mathrm{SiO}_{2}$ nanocomposites for the removal of methylene blue (MB) from aqueous solution. In addition, the adsorption kinetics, isotherms and thermodynamics of the adsorption process were also investigated. 


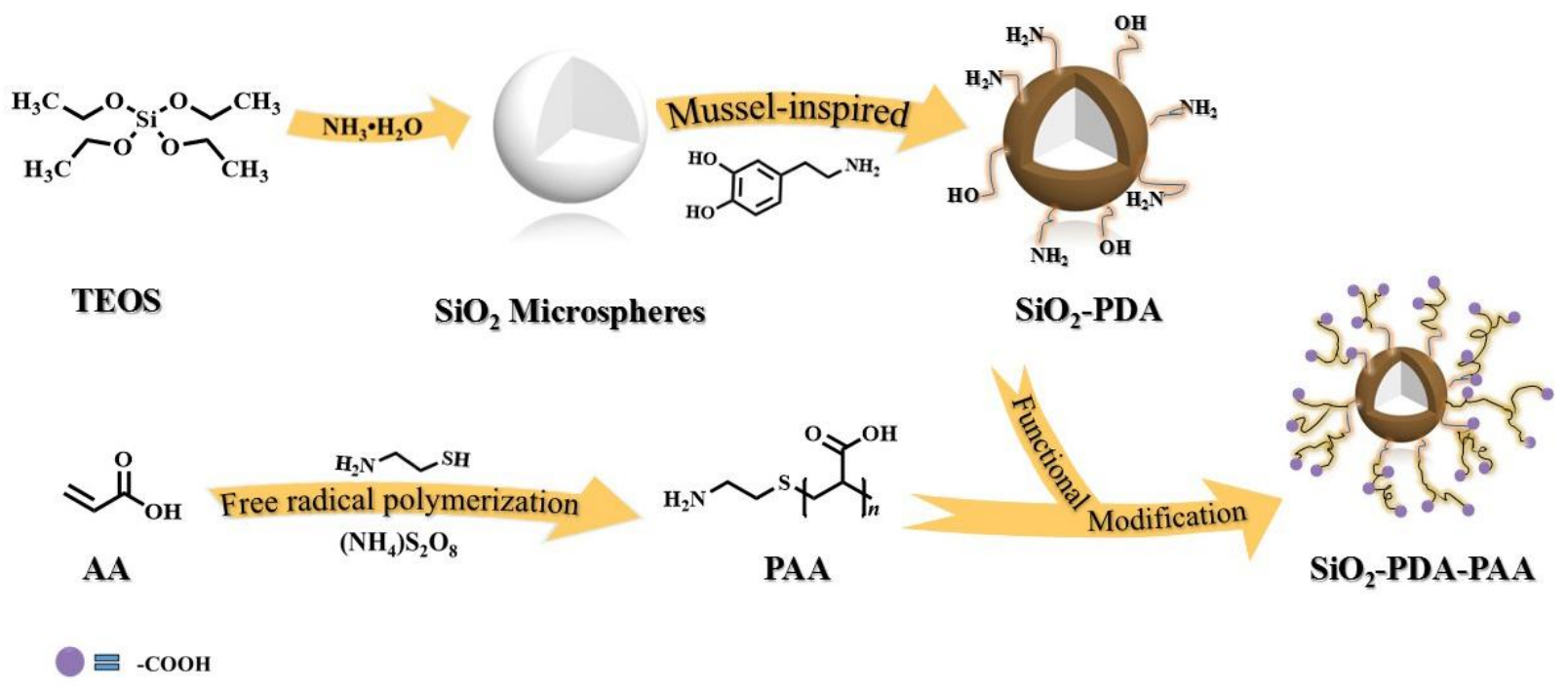

Scheme 1 Schematic showing the preparation of $\mathrm{SiO}_{2}$-PDA-PAA through a combination of mussel-inspired chemistry and Michael addition reaction.

\section{Experimental}

\subsection{Materials and methods}

\subsubsection{Materials}

All chemical reagents were used as received without further purification. All solvents were of analytical grade. Tetraethyl orthosilicate (TEOS) (> 98\%) was used to prepare monodisperse $\mathrm{SiO}_{2}$ nanoparticles. Acrylic acid (AA) (> 98\%), ammonium persulfate (APS) (> 98.5\%), dopamine hydrochloride (> 98\%) and methylene blue were all purchased from Aladdin industrial Co. Ltd. (Shanghai, China). Ammonia (28\%), tris-(chydroxymethyl)-aminethane (Tris) (> 99\%) and cysteamine hydrochloride (CSH) (98\%) were all supplied by Tianjin Heowns Biochem. Co. Ltd.

\subsubsection{Synthesis of monodisperse $\mathrm{SiO}_{2}$ nanoparticles}

The $\mathrm{SiO}_{2}$ nanoparticles were synthesized according to the Stöber method.[41-44] In a typical synthesis procedure, $36 \mathrm{~mL}$ ammonia (28\%) was mixed with $124 \mathrm{~mL}$ ethyl alcohol and $50 \mathrm{~mL}$ deionized water. Then, $18 \mathrm{~mL}$ TEOS was rapidly added into the mixture ammonia solution. After being stirred at room temperature for $6 \mathrm{~h}$, the mixture was centrifuged at $6000 \mathrm{r} / \mathrm{min}$ for $5 \mathrm{~min}$. The sediments were then washed with deionized water three times to remove unreacted reagents. A white powder was obtained and dried in vacuum oven at $60^{\circ} \mathrm{C}$ for $8 \mathrm{~h}$.

\subsubsection{Synthesis of PAA}

The amino-terminated PAA was synthesized using chain transfer free radical polymerization, in which AA was selected as the monomer and CSH as chain transfer agent. Briefly, $1.136 \mathrm{~g}(10 \mathrm{mmol}) \mathrm{CSH}, 4.564 \mathrm{~g}$ (20 mmol) APS and $14.412 \mathrm{~g}(200 \mathrm{mmol})$ AA were dissolved in $500 \mathrm{~mL}$ polymerization flask by deionized water. The mixture was stirred under nitrogen atmosphere at $80^{\circ} \mathrm{C}$ for $24 \mathrm{~h}$. The PAA was dialyzed with running water overnight to remove small molecules. The amino-terminated PAA was then precipitated with acetone and dried at $60^{\circ} \mathrm{C}$ under vacuum. 


\subsubsection{Preparation of $\mathrm{SiO}_{2}$-PDA-PAA}

The functional $\mathrm{SiO}_{2}$ nanocomposites ( $\mathrm{SiO}_{2}$-PDA-PAA) were prepared by combining mussel-inspired chemistry and a Michael addition reaction.[45] The typical procedure was described as follow: $2.0 \mathrm{~g} \mathrm{SiO}_{2}$ nanoparticles and $6.0 \mathrm{~g}$ DA were dispersed into $500 \mathrm{~mL}(10 \mathrm{mM})$ Tris buffer solution and stirred constantly at room temperature for $8 \mathrm{~h}$. The mixture was centrifuged at 8000 $\mathrm{r} / \mathrm{min}$ for $10 \mathrm{~min}$. The sediments were washed with deionized water three times. The $\mathrm{SiO}_{2}-\mathrm{PDA}$ composites were dried in a vacuum at $60{ }^{\circ} \mathrm{C}$. A secondary reaction occurred on the surface of the $\mathrm{SiO}_{2}$-PDA. The $\mathrm{SiO}_{2}-\mathrm{PDA}(2.0 \mathrm{~g})$ and $6.0 \mathrm{~g}$ of PAA were added to $100 \mathrm{~mL} 10 \mathrm{mM}$ Tris buffer solution. This mixture was stirred for $8 \mathrm{~h}$ at room temperature, and the final products were separated by centrifugation at $10000 \mathrm{rpm}$ and dried at $60^{\circ} \mathrm{C}$ in a vacuum oven.

\subsubsection{Characterization of absorbents}

The size and morphology features of the $\mathrm{SiO}_{2}$ samples were characterized by TEM (Hitachi-7650B, Japan). FT-IR spectra were recorded on a Nicolet 380 Fourier transform spectrometer instrument from $4000-400 \mathrm{~cm}^{-1}$ in transmission mode. TGA was performed under nitrogen atmosphere at a flow rate of $100 \mathrm{~mL} / \mathrm{min}$ using a SDTQ600 TGA instrument. The heating rate was set at $15^{\circ} \mathrm{C} / \mathrm{min}$. The surface composition information of $\mathrm{SiO}_{2}$ nanoparticles, $\mathrm{SiO}_{2}$-PDA and $\mathrm{SiO}_{2}$-PDA-PAA nanocomposites was determined using an XPS (VGESCALAB 220-IXL) with Al Ka X-ray source.

\subsection{Absorption studies}

Batch adsorption experiments investigated the adsorption performance and effects of experimental parameters (e.g. contact time, solution $\mathrm{pH}$, temperature and initial concentrations) on the adsorption process. Here, a cationic dye (MB) was selected as the adsorbate to study the adsorption performance. The effect of contact time used $50 \mathrm{~mL} \mathrm{MB}$ solution $(50 \mathrm{mg} / \mathrm{L})$ with $10 \mathrm{mg}$ adsorbents at room temperature $\left(25^{\circ} \mathrm{C}\right)$ for $120 \mathrm{~min}$. The instantaneous MB concentrations at different times $t$ (min) were detected by an ultraviolet and visible spectrophotometer (TU-1810) instrument at $664 \mathrm{~nm}$. The influence of solution $\mathrm{pH}$ was studied by adjusting the $\mathrm{pH}$ values of the $\mathrm{MB}$ solution $(50 \mathrm{mg} / \mathrm{L})$ to $2.0,3.0,4.0,5.0,6.0,7.0,8.0,9.0,10.0,11.0$ and $12.0 \mathrm{using} 0.1 \mathrm{M} \mathrm{HCl}$ and $0.1 \mathrm{M} \mathrm{NaOH}$. Temperatures included 298, 303, 313, 323, 333 and $343 \mathrm{~K}$. The influence of initial concentration on $\mathrm{MB}$ removal capability was studied by agitating different concentrations (25-250 mg/L) MB solution with the same amount of adsorbent (10 mg) for $120 \mathrm{~min}$.

The adsorption capacity at equilibrium time $\left(Q_{e}\right)$ and removal efficiency $(R(\%))$ were determined by equations:

$$
Q_{\mathrm{e}}=\left(\frac{C_{0}-C_{e}}{m}\right) \times V \quad R(\%)=\left(\frac{C_{0}-C_{e}}{C_{0}}\right) \times 100
$$

Where $C_{0}$ and $C_{e}$ are initial and equilibrium concentrations of MB. Here, $m$ is the amount of adsorbent (g), and $V$ is the volume of solution (L).

The adsorption capacity at any time $t, Q_{t}(\mathrm{mg} / \mathrm{g})$ is calculated based on the following equation:

$$
Q_{t}=\left(\frac{C_{0}-C_{t}}{m}\right) \times V
$$

Where $C_{t}(\mathrm{mg} / \mathrm{L})$ is the $\mathrm{MB}$ concentration at any time $t(\mathrm{~min})$, and $C_{0}(\mathrm{mg} / \mathrm{L})$ is the initial $\mathrm{MB}$ concentration. $V(\mathrm{~L})$ is the 
volume of solution in this batch experiment, and $m(\mathrm{~g})$ is the amount of adsorbent in the adsorption process.

\section{Results and discussion}

\subsection{Characterization of $\mathrm{SiO}_{2}, \mathrm{SiO}_{2}$-PDA and $\mathrm{SiO}_{2}$-PDA-PAA nanocomposites}

The TEM images of $\mathrm{SiO}_{2}$ nanoparticles, $\mathrm{SiO}_{2}-\mathrm{PDA}$ and $\mathrm{SiO}_{2}-\mathrm{PDA}-\mathrm{PAA}$ nanoparticles are described in Fig. 1. The $\mathrm{SiO}$ particles showed a spherical morphology. The diameter of raw $\mathrm{SiO}_{2}$ particles is 100 to $200 \mathrm{~nm}$ (Fig. 1A). Fig. 1B presents TEM images of $\mathrm{SiO}_{2}-\mathrm{PDA}$, and there is little difference between the as-prepared $\mathrm{SiO}_{2}$ nanoparticles and the $\mathrm{SiO}_{2}-\mathrm{PDA}$. However, some polymer films around these $\mathrm{SiO}_{2}$ nanoparticles can be observed in the $\mathrm{SiO}_{2}$ nanoparticles (Fig. 1B). These results implied that $\mathrm{SiO}_{2}$ nanoparticles were coated with polymers through self-polymerization of DA. Fig. 1C and Fig. 1D present TEM images of $\mathrm{SiO}_{2}$-PDA-PAA. Versus the as-prepared $\mathrm{SiO}_{2}$ nanoparticles, some gauzy extended layers appeared on the surface of the $\mathrm{SiO}_{2}$-PDA-PAA. Although the spherical morphology of $\mathrm{SiO}_{2}$ nanoparticles can still be observed in $\mathrm{SiO}_{2}$-PDA-PAA, the morphology of these $\mathrm{SiO}_{2}$ nanoparticles became very blurry. It is difficult to find the boundary between the individual particles. Other than TEM images, the optical images of these $\mathrm{SiO}_{2}$ powders are shown in the insets of Fig. 1. The color of these samples changes from white to dark brown implying that the PDA thin films were coated on the $\mathrm{SiO}_{2}$ nanoparticles through self-polymerization.
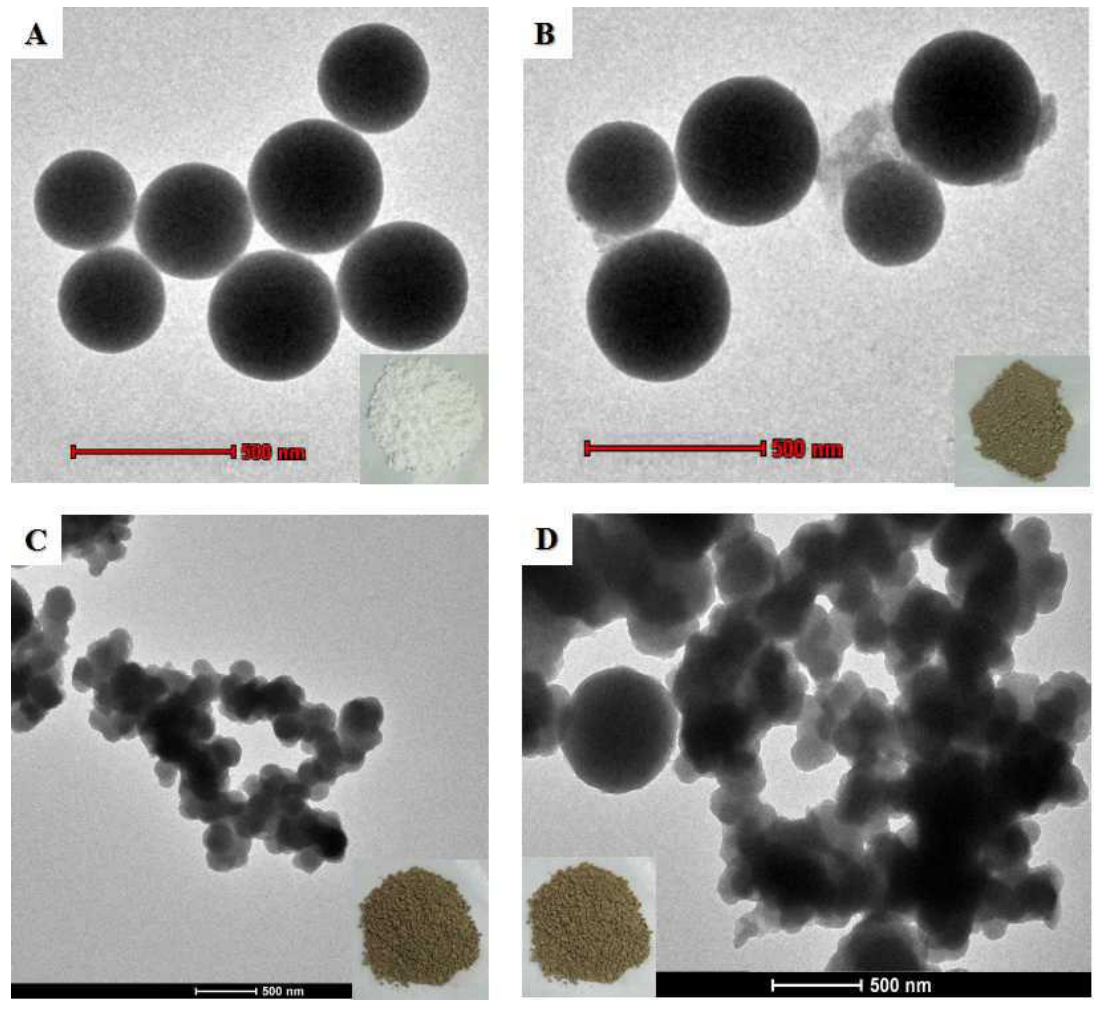

Fig. 1 TEM images of (A) $\mathrm{SiO}_{2}$ nanoparticles, (B) $\mathrm{SiO}_{2}-\mathrm{PDA}$ and (C, D) $\mathrm{SiO}_{2}-\mathrm{PDA}-\mathrm{PAA}$. Scale bar $=500 \mathrm{~nm}$. The insets are the optical images of $\mathrm{SiO}_{2}$ nanoparticles, $\mathrm{SiO}_{2}$-PDA and $\mathrm{SiO}_{2}$-PDA-PAA. The color change implied that the PDA thin films were covered on the surface of $\mathrm{SiO}_{2}$ nanoparticles.

We used FT-IR analysis to further identify characteristic functional groups on the $\mathrm{SiO}_{2} \mathrm{samples}$ The samples of raw $\mathrm{SiO}$ nanoparticles, $\mathrm{SiO}_{2}$-PDA and $\mathrm{SiO}_{2}$-PDA-PAA were analyzed and are shown in Fig. 2 (A). The broad peak at $3396.5 \mathrm{~cm}^{-1}$ was the 
- OH stretching vibration. This originated from the surface hydroxyls of silica and PAA. This peak was easily observed in the samples of both raw $\mathrm{SiO}_{2}$ nanoparticles and $\mathrm{SiO}_{2}$-PDA-PAA nanocomposites. The peaks at $1110.9,804.3$ and $474.5 \mathrm{~cm}^{-1}$ were associated with $\mathrm{Si}-\mathrm{OH}$ stretching vibration and $\mathrm{Si}-\mathrm{O}-\mathrm{Si}$ symmetric stretching vibration peaks, respectively. The peaks at 1714.6 and $1627.9 \mathrm{~cm}^{-1}$ were attributed to the $\mathrm{C}=\mathrm{O}$ stretching vibration in the $-\mathrm{COOH}$ groups. This could be observed in the FT-IR spectrum of $\mathrm{SiO}_{2}$-PDA-PAA. In addition, peaks from 1454.1 to $1384.8 \mathrm{~cm}^{-1}$ in $\mathrm{SiO}_{2}$-PDA-PAA can be ascribed to the C-H bending vibration from PAA. Of note, the intensity of the stretching vibration of the $\mathrm{CH}_{3}$ and $\mathrm{CH}_{2}$ is decreased after surface coating of $\mathrm{SiO}_{2}$ nanoparticles with PDA. However, the intensity of these peaks increased after the $\mathrm{SiO}_{2}-\mathrm{PDA}$ surface was coated with PAA. These changes indicated that PDA and PAA were successively immobilized on the surface of $\mathrm{SiO}_{2}$ nanoparticles through a mussel-inspired surface coating and subsequent Michael addition.

Fig. 2 (B) shows the TGA curves of $\mathrm{SiO}_{2}$ nanoparticles, $\mathrm{SiO}_{2}$-PDA and $\mathrm{SiO}_{2}$-PDA-PAA from 298 to $870 \mathrm{~K}$. Based on the TGA data, the weight loss of original $\mathrm{SiO}_{2}$ nanoparticles reached $9.74 \%$ when the temperature was $860 \mathrm{~K}$. However, the weight loss of $\mathrm{SiO}_{2}$-PDA increased to $12.74 \%$ in the $\mathrm{SiO}_{2}$-PDA sample. The weight loss of $\mathrm{SiO}_{2}$-PDA is obviously greater than that of the original $\mathrm{SiO}_{2}$ nanoparticles. This implied that the PDA films are coated on $\mathrm{SiO}_{2}$ nanoparticles via self-polymerization of DA. The weight loss of the $\mathrm{SiO}_{2}$-PDA-PAA increased further to $15.91 \%$ under the same test parameters suggesting successful immobilization of PAA on $\mathrm{SiO}_{2}$-PDA through a Michael addition. In sum, we concluded that the PAA was immobilized on the surface of the $\mathrm{SiO}_{2}$ nanoparticles through a combination of mussel-inspired chemistry and a Michael addition reaction.

A

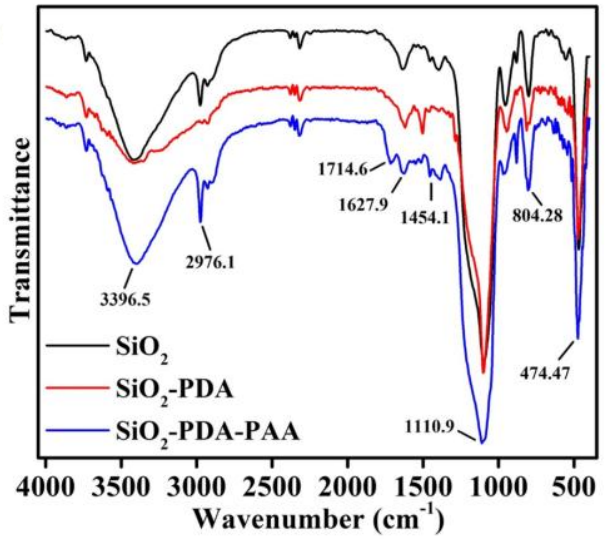

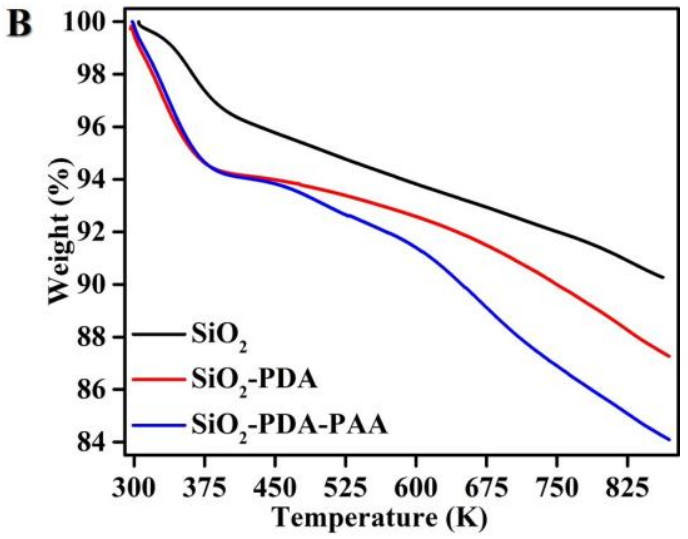

Fig. 2 (A) FT-IR spectra of $\mathrm{SiO}_{2}$ nanoparticles, $\mathrm{SiO}_{2}$-PDA and $\mathrm{SiO}_{2}$-PDA-PAA; (B) TGA curves of $\mathrm{SiO}_{2}$ nanoparticles, $\mathrm{SiO}_{2}$-PDA and $\mathrm{SiO}_{2}$-PDA-PAA.

The surface chemical information was further confirmed with XPS. Fig. S1 shows the C1s, N1s, O1s and Si2p XPS peaks for the $\mathrm{SiO}_{2}$ samples. The survey XPS spectra indicated that the $\mathrm{SiO}_{2}$ samples were composed of $\mathrm{C}, \mathrm{N}$, O and $\mathrm{Si}$. The detailed elemental information of $\mathrm{SiO}_{2}$ nanoparticles, $\mathrm{SiO}_{2}-\mathrm{PDA}$ and $\mathrm{SiO}_{2}-\mathrm{PDA}-\mathrm{PAA}$ can be further obtained from C1s, N1s, O1s and $\mathrm{Si} 2 \mathrm{p}$ XPS spectra (Fig. 3). The binding energy peaks of $\mathrm{C} 1 \mathrm{~s}, \mathrm{~N} 1 \mathrm{~s}, \mathrm{O} 1 \mathrm{~s}$ and $\mathrm{Si} 2 \mathrm{p}$ XPS spectra in the sample of $\mathrm{SiO}_{2}$ nanoparticles were found at 284.81, 398.43, 533.07 and $103.8 \mathrm{eV}$, respectively. However, the binding energy peaks of these XPS spectra in the sample of $\mathrm{SiO}_{2}$-PDA shifted to 284.68, 400.03, 532.8 and $103.53 \mathrm{eV}$ for $\mathrm{C} 1 \mathrm{~s}, \mathrm{~N} 1 \mathrm{~s}, \mathrm{O} 1 \mathrm{~s}$ and $\mathrm{Si} 2 \mathrm{p}$, respectively. Fig. 3A shows the C1s 
spectra of the $\mathrm{SiO}_{2}$ samples. The C1s intensity of $\mathrm{SiO}_{2}-\mathrm{PDA}$ and $\mathrm{SiO}_{2}-\mathrm{PDA}-\mathrm{PAA}$ is obviously stronger than that of the original $\mathrm{SiO}_{2}$ nanoparticles. This indicates the successful modification of $\mathrm{SiO}_{2}$ with $\mathrm{PDA}$ and PAA. In addition, a small peak at 288.68 eV was found in the $\mathrm{C} 1$ s spectra of $\mathrm{SiO}_{2}$-PDA-PAA. This is attributed to the $\mathrm{C}=\mathrm{O}$ band of PAA. These results confirmed that PAA was truly conjugated to the $\mathrm{SiO}_{2}$ nanoparticles via a combination of mussel-inspired chemistry and Michael addition.

More importantly, almost no N1s signal was found in the raw $\mathrm{SiO}_{2}$ nanoparticles. However, the N1s signal was obvious in the $\mathrm{SiO}_{2}$-PDA and $\mathrm{SiO}_{2}$-PDA-PAA samples. This clearly implied that the PDA films were coated on the surface of the $\mathrm{SiO}_{2}$ nanoparticles. Furthermore, versus $\mathrm{SiO}_{2}-\mathrm{PDA}$, the intensity of the N1s spectra decreased in the sample of $\mathrm{SiO}_{2}-\mathrm{PDA}-\mathrm{PAA}$. This indicated that PAA can be conjugated to the $\mathrm{SiO}_{2}$-PDA through a Michael addition reaction. All of these detailed XPS spectra provide firm evidence for the successful modification of $\mathrm{SiO}_{2}$ nanoparticles via mussel-inspired chemistry and subsequent immobilization of amino-terminated PAA on the $\mathrm{SiO}_{2}$-PDA through a Michael addition.
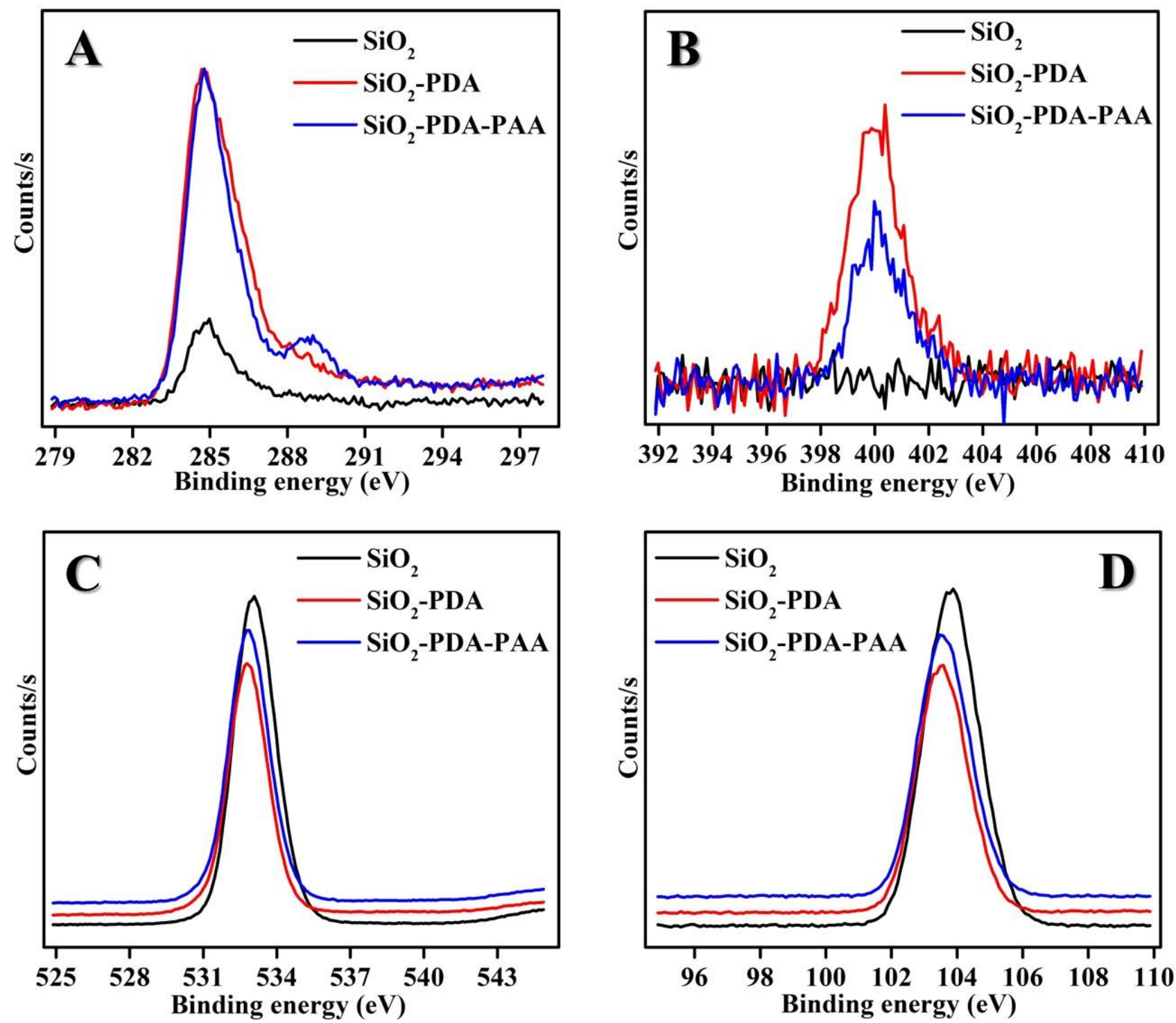

Fig. 3 High-resolution XPS spectra of C1s (A), N1s (B), O1s (C), and Si2p (D) for raw $\mathrm{SiO}_{2}, \mathrm{SiO}_{2}-\mathrm{PDA}$ and SiO ${ }_{2}$-PDA-PAA.

Table 1 shows the elemental contents of $\mathrm{SiO}_{2}$ samples based on $\mathrm{C} 1 \mathrm{~s}, \mathrm{~N} 1 \mathrm{~s}, \mathrm{O} 1 \mathrm{~s}$, and $\mathrm{Si} 2 \mathrm{p}$ spectra. The elemental contents of $\mathrm{C} 1 \mathrm{~s}$ and $\mathrm{N} 1 \mathrm{~s}$ increased from $4.15 \%$ and $0.36 \%$ to $21.55 \%$ and $1.96 \%$ after $\mathrm{SiO}_{2}$ nanoparticles were coated by PDA. The O1s and 
Si2p decreased from $65.07 \%$ and $30.41 \%$ to $52.77 \%$ and 23.72 , respectively. Versus $\mathrm{SiO}_{2}-\mathrm{PDA}$, the elemental contents of C1s and $\mathrm{N} 1 \mathrm{~s}$ in the $\mathrm{SiO}_{2}$-PDA-PAA decreased from $21.55 \%$ and 1.96 to $18.62 \%$ and $1.31 \%$, respectively. In contrast, the intensity of the O1s increased after the $\mathrm{SiO}_{2}$-PDA became surface conjugated with PAA. These comparisons indicated that $\mathrm{SiO}_{2}$ nanoparticles could be truly modified by amino-terminated polymers via mussel-inspired chemistry and a Michael addition. Furthermore, based on the XPS data, the mass ratio of $\mathrm{SiO}_{2}$ to PDA was estimated to be $2.37: 1$. The weight percentage of PAA in $\mathrm{SiO}_{2}$-PDA-PAA was $33.16 \%$.

Table 1 Element contents (\%) of $\mathrm{SiO}_{2}$ nanoparticles, $\mathrm{SiO}_{2}-\mathrm{PDA}$ and $\mathrm{SiO}_{2}-\mathrm{PDA}-\mathrm{PAA}$ based on XPS analysis.

\begin{tabular}{lllll}
\hline \multirow{2}{*}{ Sample } & \multicolumn{4}{c}{ Atom percentage (\%) } \\
\cline { 2 - 5 } & $\mathbf{C 1 s}$ & N1s & O1s & Si2p \\
\hline $\mathrm{SiO}_{2}$ & 4.15 & 0.36 & 65.07 & 30.41 \\
$\mathrm{SiO}_{2}$-PDA & 21.55 & 1.96 & 52.77 & 23.72 \\
$\mathrm{SiO}_{2}$-PDA-PAA & 18.62 & 1.31 & 56.09 & 23.97 \\
\hline
\end{tabular}

\subsection{Adsorption experiment studies}

\subsubsection{The effect of contact time and adsorption kinetics}

The adsorption performance of synthesized adsorbents is shown in Fig. 4 (A). The $\mathrm{SiO}_{2}$-PDA-PAA showed much higher adsorption efficiency towards $\mathrm{MB}$ than the original $\mathrm{SiO}_{2}$ nanoparticles. The adsorption of $\mathrm{MB}$ by $\mathrm{SiO}_{2}-\mathrm{PDA}-\mathrm{PAA}$ increased rapidly within $10 \mathrm{~min}$. The adsorption equilibrium time of both $\mathrm{SiO}_{2}$ nanoparticles and the $\mathrm{SiO}_{2}$-PDA-PAA is about 50 min. The adsorption capability of $\mathrm{MB}$ by $\mathrm{SiO}_{2}$-PDA-PAA was found to be $150.02 \mathrm{mg} / \mathrm{g}$, while adsorption capacity of original $\mathrm{SiO}_{2}$ nanoparticles was just $43.87 \mathrm{mg} / \mathrm{g}$. The significant increase in adsorption capability of the modified $\mathrm{SiO}_{2}$ nanocomposites implied that PAA was indeed immobilized on the surface of the $\mathrm{SiO}_{2}-\mathrm{PDA}$. This high adsorption capacity indicated that the $\mathrm{SiO}_{2}$-PDA-PAA favored adsorption of MB.
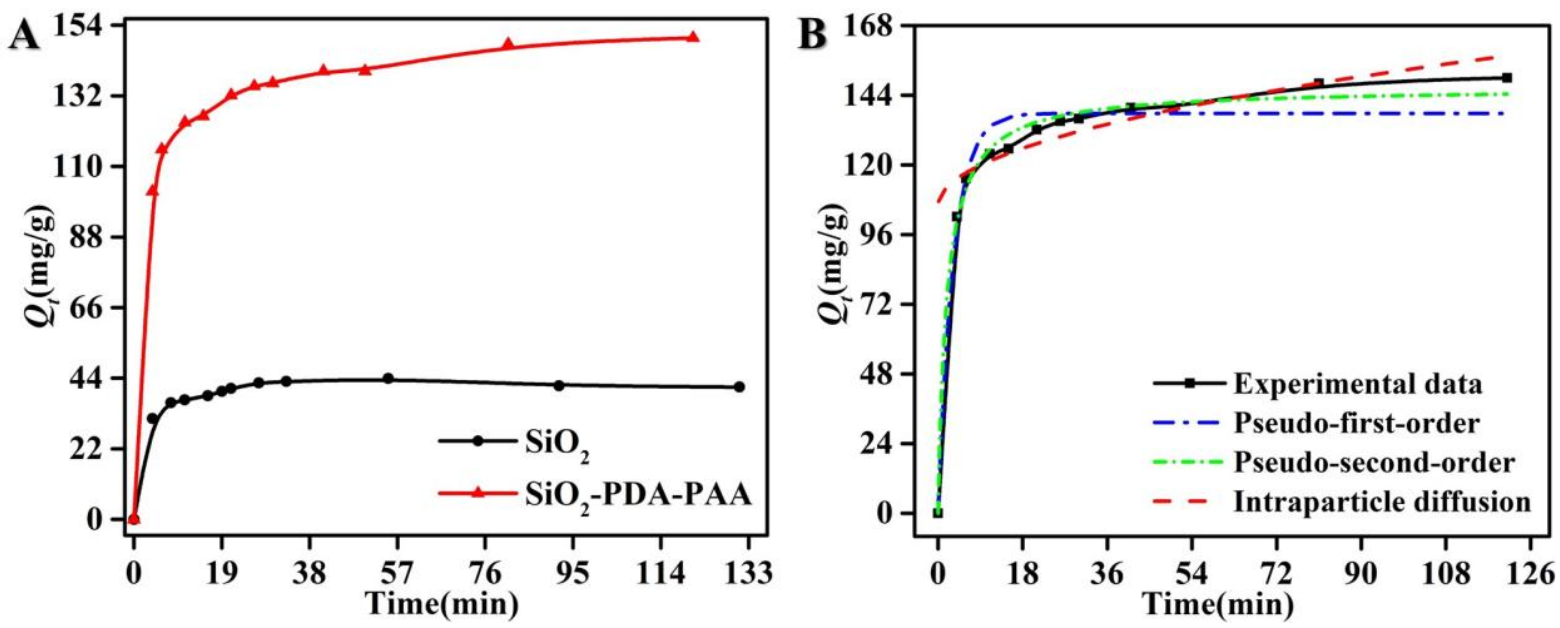

Fig. 4 (A) The adsorption capacity of original $\mathrm{SiO}_{2}$ nanoparticles and $\mathrm{SiO}_{2}$-PDA-PAA towards $50 \mathrm{mg} / \mathrm{L}$ MB at room temperature, 
initial $\mathrm{pH}=7.1$, and adsorbent dose $10 \mathrm{mg}$. (B) Kinetic curves for adsorption of $\mathrm{MB}$ onto $\mathrm{SiO}_{2}$-PDA-PAA.

The adsorption kinetic models play an important role in describing adsorption mechanism, which can predict the adsorption rate and equilibrium adsorption capacity.[46] Here, three commonly used adsorption kinetic models were employed to investigate the adsorption mechanism including the pseudo-first-order, pseudo-second-order and intra-particle diffusion kinetic models.

The pseudo-first-order rate equation is:

$$
Q_{t}=Q_{e}\left(1-e^{-k_{1} t}\right)
$$

Here, $Q_{e}(\mathrm{mg} / \mathrm{g})$ is the amount of adsorbed MB per unit mass of $\mathrm{SiO}_{2}$-PDA-PAA at equilibrium, and $Q_{t}(\mathrm{mg} / \mathrm{g})$ is the amount of adsorbed MB at time $t(\mathrm{~min})$. Term $k_{l}\left(\mathrm{~min}^{-1}\right)$ is the rate constant of adsorption. The values of those parameters were calculated from the pseudo-first-order rate equation and listed in the following table.

The pseudo-second-order kinetic model was described by following equation[47]:

$$
\begin{aligned}
& Q_{t}=\frac{k_{2} Q_{e}^{2} t}{1+k_{2} Q_{e} t} \\
& h=k_{2} Q_{e}^{2}
\end{aligned}
$$

Here, $k_{2}\left(\mathrm{~g} \mathrm{mg}^{-1} \mathrm{~min}^{-1}\right)$ is the pseudo-second-order rate constant and $h(\mathrm{mg} / \mathrm{g} \mathrm{min})$ represents the initial adsorption rate. The values of $k_{2}$ and $h$ were calculated from the equation mentioned above and is listed in Table 2 . The experimental kinetic data were fitted by a pseudo-first-order and pseudo-second-order models. The results are presented in Fig. 4(B). Based on the data in Table 2, the calculated value of $Q_{e}$ from the pseudo-second-order was $146.6 \mathrm{mg} / \mathrm{g}$. The $Q_{e}$ from the pseudo-first-order was $137.8 \mathrm{mg} / \mathrm{g}$. The value of $Q_{e}$ from the pseudo-second-order was closer to the $Q_{e}$ from the adsorption experiment $(150.02 \mathrm{mg} / \mathrm{g})$, which indicated that the adsorption process of $\mathrm{SiO}_{2}$-PDA-PAA to $\mathrm{MB}$ followed a pseudo-second-order. Furthermore, correlation coefficient values $\left(R^{2}=0.9931\right)$ from the pseudo-second-order were found to be higher than the pseudo-first-order $\left(R^{2}=0.9674\right)$. These results suggest that the adsorption procedure is better fitted as a pseudo-second-order than a pseudo-first-order.

The intra-particle diffusion model based on the Weber-Morris equation evaluated the steps of adsorption:

$$
Q_{t}=k_{p} t^{0.5}+C
$$

Here, $k_{p}\left(\mathrm{mg} \mathrm{g}^{-1} \min ^{-1 / 2}\right)$ is the rate constant of the intra-particle diffusion and is calculated from the equation listed above. The parameter $C$ is a constant given an idea about the effect of the boundary layer.[48] Fig. 4(B) shows the non-liner fitting curve of intra-particle diffusion. The values of these parameters are listed in Table 2. The low correlation coefficient $\left(R^{2}=0.8207\right)$ from intra-particle diffusion model indicated that adsorption of $\mathrm{MB}$ by $\mathrm{SiO}_{2}-\mathrm{PDA}-\mathrm{PAA}$ was not the rate limiting step. The intra-particle diffusion for the adsorption process was not significant.

Table 2 Data for pseudo-first-order, pseudo-second-order and intraparticle diffusion models parameters at $298 \mathrm{~K}$. 
Pseudo-first-order equation

$Q_{e(c a l)}(\mathrm{mg} / \mathrm{g})$

137.80

$$
\begin{aligned}
& k_{l}\left(\min ^{-1}\right) \\
& R^{2}
\end{aligned}
$$

Pseudo-second-order equation

$$
\begin{aligned}
& Q_{e(c a l)}(\mathrm{mg} / \mathrm{g}) \\
& k_{2}\left(\mathrm{~g} \mathrm{mg}^{-1} \mathrm{~min}^{-1}\right) \\
& h\left(\mathrm{mg} \mathrm{g}^{-1} \mathrm{~min}^{-1}\right)
\end{aligned}
$$

$R^{2}$

Intra-particle diffusion

$$
\begin{aligned}
& k_{p}\left(\mathrm{mg} \mathrm{g}^{-1} \mathrm{~min}^{-0.5}\right) \\
& C \\
& R^{2}
\end{aligned}
$$

\subsubsection{Adsorption isotherms}

Adsorption isotherms describe the adsorption behavior for a solid-solution adsorption system. The adsorption isotherm can explain the distribution of adsorbate between the solid and liquid phases when the adsorption reaction reached equilibrium.[49] In this study, the adsorption isotherm was applied to understand the adsorption mechanism. Both the Langmuir and Freundlich adsorption isotherm models fitted the equilibrium data. Of these, the Langmuir model is one of the most widely used adsorption isotherms for the solid-solution adsorption system. The adsorption constants from the Langmuir isotherm explain the adsorption mechanism. The Langmuir isotherm model is based on an assumption that adsorption occurs on the monolayer and homogeneous surface of adsorbents. This is irrelevant to the degree of surface coverage. The non-liner formation of the Langmuir isotherm model was listed as follows:

$$
Q_{e}=\frac{K_{L} Q_{m} C_{e}}{1+K_{L} C_{e}}
$$

Here, $Q_{m}(\mathrm{mg} / \mathrm{g})$ is the theoretical maximum adsorption capacity of absorbents, and $K_{L}(\mathrm{~L} / \mathrm{mg})$ is the Langmuir adsorption constant. The $Q_{e}(\mathrm{mg} / \mathrm{g})$ is the equilibrium adsorption capacity per unit weight of adsorbents. Term $C_{e}$ is the equilibrium MB concentration $(\mathrm{mg} / \mathrm{L})$.

This essential feature of the Langmuir isotherm model was expressed in term of a dimensionless factor:

$$
R_{L}=\frac{1}{1+K_{L} C_{0}}
$$

Here, $K_{L}(\mathrm{~L} / \mathrm{mg})$ is a constant of the Langmuir model. Term $C_{0}$ is the initial MB concentration $(\mathrm{mg} / \mathrm{L})$ and $R_{L}$ is the dimensionless separation factor. The parameter $R_{L}$ indicates that the type of Langmuir isotherm can be either irreversible $\left(R_{L}=0\right.$, favorable $\left(0<R_{L}<1\right)$, linear $\left(R_{L}=1\right)$, or unfavorable $\left(R_{L}>1\right)[50]$. All relative parameters from the Langmuir isotherm were calculated and listed in Table 3 according to nonlinear analysis. Fig. 5 shows the fitting equilibrium curve from the Langmuir isotherm model. 


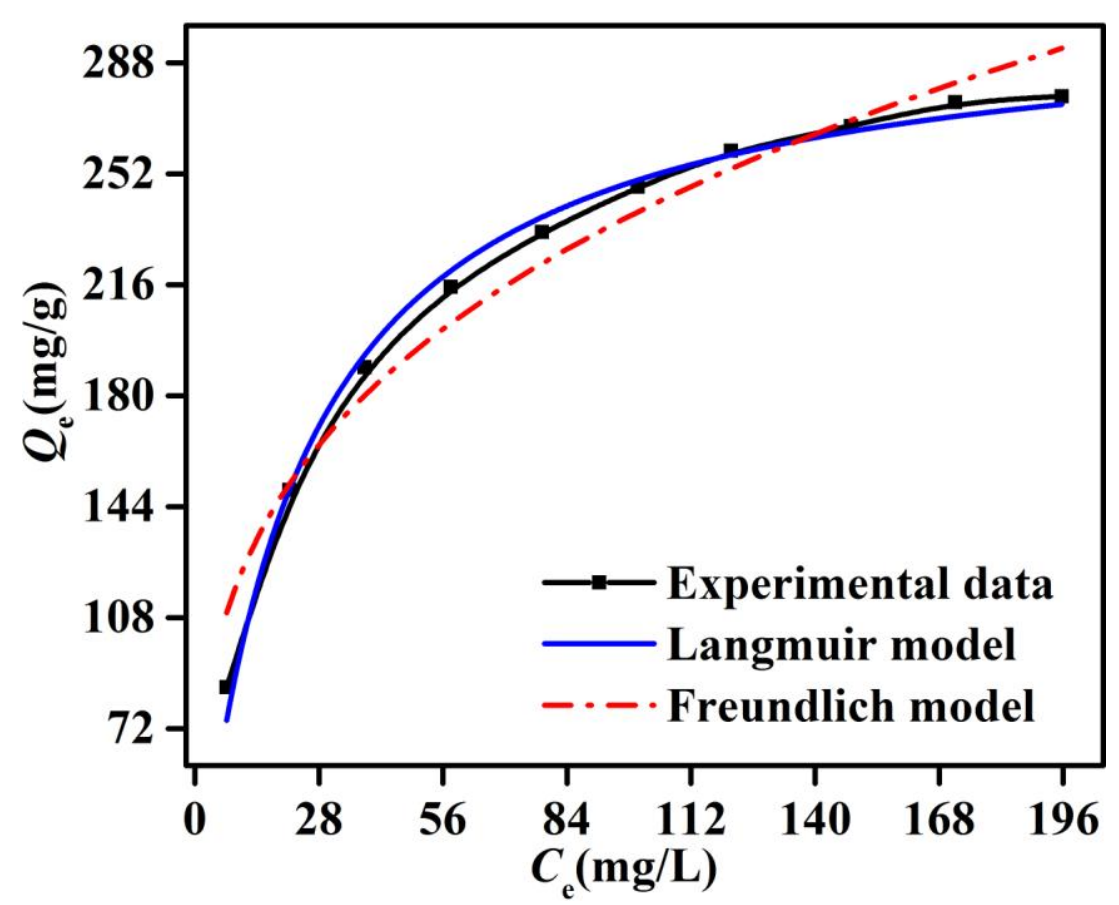

Fig. 5 The isotherm curves for the adsorption of $\mathrm{MB}$ molecules onto the functionalized $\mathrm{SiO}_{2}$ nanocomposites.

The experimental adsorption data were also fitted with the Freundlich isotherm model. This model is based on the hypothesis that non-ideal sorption occurs on the heterogeneous surfaces. The adsorption capacity is related to the adsorbate concentration at equilibrium.[45] The non-linear form of the Freundlich isotherm model can be expressed as:

$$
Q_{e}=K_{F} C_{e}^{\frac{1}{n}}
$$

Here, $K_{F}\left[(\mathrm{mg} / \mathrm{g})(\mathrm{L} / \mathrm{mg})^{1 / \mathrm{n}}\right]$ is the Freundlich isotherm adsorption equilibrium constant related to the adsorption capacity, and $n$ is the heterogeneity constant related to the intensity of the adsorption interactions. Generally speaking, $n$ negatively correlates with adsorption performance. When the value of $1 / n$ is equal to 1 , the adsorption is essentially homogeneous and there is no interaction among the adsorbed species. The adsorption is favorable when the value of $1 / n$ is between 0 and 1 . However, adsorption is unfavorable when the value of $1 / n$ is over 1.[51] Terms $Q_{e}(\mathrm{mg} / \mathrm{g})$ and $C_{e}(\mathrm{mg} / \mathrm{L})$ are the amount of MB adsorbed per unit mass of adsorbents and MB concentration at equilibrium, respectively. The non-linear fitting curve of the Freundlich isotherm is shown in Fig. 5. The values of the Freundlich isotherm model parameters were calculated and listed in Table 3.

Table 3 The equilibrium parameters for the adsorption of $\mathrm{MB}$ molecules onto $\mathrm{SiO}_{2}-\mathrm{PDA}-\mathrm{PAA}$ nanocomposites.

\begin{tabular}{llc}
\hline Isotherms & Parameters & Temperatures $(\mathrm{K})$ \\
\cline { 3 - 3 } & & 298 \\
\hline Langmuir & $Q_{m}(\mathrm{mg} / \mathrm{g})$ & 305.9 \\
& $K_{L}(\mathrm{~L} / \mathrm{mg})$ & 0.04469 \\
& $R_{L}$ & $0.08215-0.4723$ \\
& $R^{2}$ & 0.9929 \\
Freundlich & $K_{F}\left[(\mathrm{mg} / \mathrm{g})(\mathrm{L} / \mathrm{mg})^{1 / \mathrm{n}}\right]$ & 60.80
\end{tabular}




$$
\begin{array}{ll}
n^{-1} & 0.2978 \\
R^{2} & 0.9585
\end{array}
$$

Table 3 shows the values of the correlation coefficient $R^{2}$ from the Langmuir isotherm model $\left(R^{2}=0.9929\right)$. These were higher than the Freundlich isotherm model $\left(R^{2}=0.9585\right)$ suggesting that the experimental data are better fitted via a Langmuir model. This indicated that monolayer adsorption plays a dominant role. The maximum adsorption capacity calculated from the Langmuir isotherm model was $305.9 \mathrm{mg} / \mathrm{g}$ at $298 \mathrm{~K}$. The high correlation coefficient $\left(R^{2}>0.9\right)$ of the Freundlich and Langmuir isotherms suggest the existence of heterogeneous active sites for adsorbents and monolayer adsorption of $\mathrm{MB}$ onto $\mathrm{SiO}_{2}$-PDA-PAA. In addition, the calculated value of the dimensionless constant $R_{L}$ ranged from 0.08215 to 0.4273 for different initial MB concentrations. This showed that the adsorption of MB was favorable. Moreover, the value of $n$ was 0.2978 suggesting that the $\mathrm{SiO}_{2}$-PDA-PAA nanocomposites were excellent at adsorbing MB.

\subsubsection{The effect of $\mathrm{pH}$}

The $\mathrm{pH}$ plays an important role in the adsorption process.[52] To study the effect of initial $\mathrm{pH}$ on adsorption of MB by $\mathrm{SiO}_{2}$-PDA-PAA, a batch experiment was carried out at different $\mathrm{pH}$ values between 2.0 and 12.0 and room temperature. Fig. 6 shows that the $\mathrm{pH}$ of the MB solution had a significant effect on the adsorption of MB by the $\mathrm{SiO}_{2}$-PDA-PAA. The value of $Q_{e}$ increased from 133.5 to $214.3 \mathrm{mg} / \mathrm{g}$ with increases in solution $\mathrm{pH}$. The MB removal efficiency was $87.4 \%$ at $\mathrm{pH}$ 11.0. This suggested that the $\mathrm{SiO}_{2}$-PDA-PAA is highly efficient for $\mathrm{MB}$ removal. The $\mathrm{pH}$ is a crucial factor affecting the adsorption process.

The lower adsorption capacity in acidic solution can be ascribed to the competitive adsorption between $\mathrm{H}^{+}$and adsorption active sites. The high concentration of $\mathrm{H}^{+}$inhibited the adsorption of $\mathrm{MB}$ by $\mathrm{SiO}_{2}$-PDA-PAA. At higher $\mathrm{pH}$, more carboxyl groups on the $\mathrm{SiO}_{2}$-PDA-PAA were ionized. Therefore, the $\mathrm{SiO}_{2}$-PDA-PAA nanocomposites favor adsorption towards $\mathrm{MB}$ with higher adsorption efficiency. The slight change of adsorption capacity at $\mathrm{pH} 12.0$ might be due to the fact that PDA in strong base was broken slightly. In conclusion, the adsorption of $\mathrm{MB}$ by $\mathrm{SiO}_{2}$-PDA-PAA was $\mathrm{pH}$-dependent. $\mathrm{pH}$ increases promoted adsorption of $\mathrm{SiO}_{2}$-PDA-PAA nanocomposites towards MB.

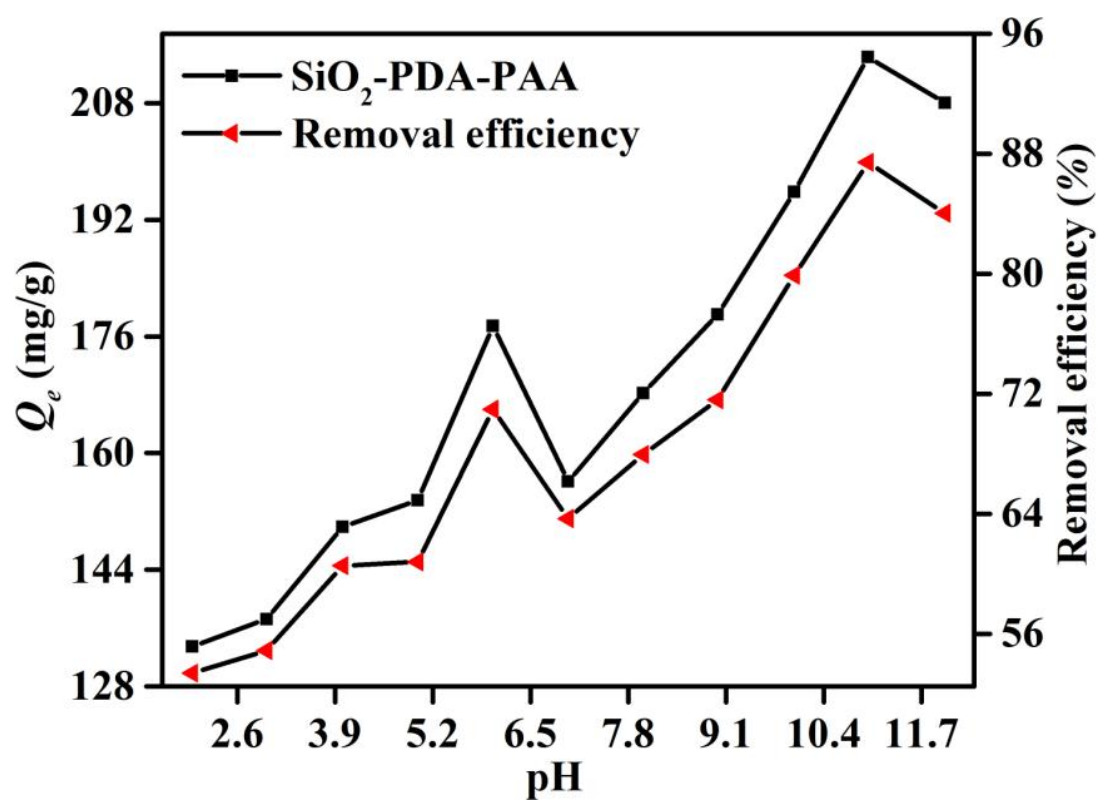

Fig. 6 The effect of solution $\mathrm{pH}$ on the adsorption of $\mathrm{MB}$ by $\mathrm{SiO}_{2}$-PDA-PAA. Experimental conditions: adsorbent dose: $10 \mathrm{mg}, \mathrm{T}$ 
$=$ room temperature.

\subsubsection{The effect of temperature and adsorption thermodynamics}

Temperature is generally considered an essential parameter to influence MB adsorption at the solid-liquid interfaces.[53] Batch adsorption experiments were carried out under from 295 to 343 K. Fig. 7 (A) shows that the adsorption capability of $\mathrm{SiO}_{2}$-PDA-PAA towards MB decreased from 149.7 to $112.2 \mathrm{mg} / \mathrm{g}$ as temperature increased from 295 to $343 \mathrm{~K}$. This indicated that the adsorption of $\mathrm{MB}$ onto $\mathrm{SiO}_{2}$-PDA-PAA nanocomposites was an exothermic process. The high temperature was not beneficial for the adsorption of $\mathrm{MB}$ by $\mathrm{SiO}_{2}$-PDA-PAA. This might be because the surface tension of the solution decreased with increasing temperature. This lead to low adsorption capacity. Thermodynamic studies provide further information about the adsorption process according to the inherent energetic changes.[54] Here, the related thermodynamic parameters including entropy $\left(\Delta S^{0}\right)$, enthalpy $\left(\Delta H^{0}\right)$ and Gibbs free energy $\left(\Delta G^{0}\right)$ were employed to evaluate the adsorption of MB by $\mathrm{SiO}_{2}$-PDA-PAA nanocomposites. The values of thermodynamic parameters were calculated by following equations:

$$
\begin{aligned}
& \ln K \alpha=\frac{\Delta S^{0}}{R}-\frac{\Delta H^{0}}{R \cdot T} \\
& K \alpha=\frac{Q_{e}}{C_{e}} \\
& \Delta G^{0}=-R T \ln K \alpha
\end{aligned}
$$

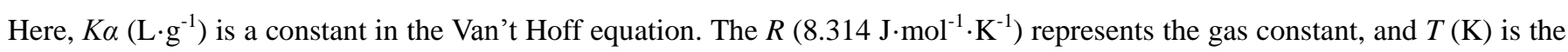
temperature. Terms $Q_{e}\left(\mathrm{mg} \cdot \mathrm{g}^{-1}\right)$ and $C_{e}\left(\mathrm{mg} \cdot \mathrm{L}^{-1}\right)$ are the amount of adsorbed $\mathrm{MB}$ at equilibrium time and the equilibrium concentration of MB solution, respectively. The thermodynamic parameters $\left(\Delta H^{0}\right.$ and $\left.\Delta S^{0}\right)$ were calculated from the slope and intercept of the Van't Hoff plots of $\ln K \alpha$ versus of $1 / T$ (Fig. 7 (B)) and are listed in Table 4.
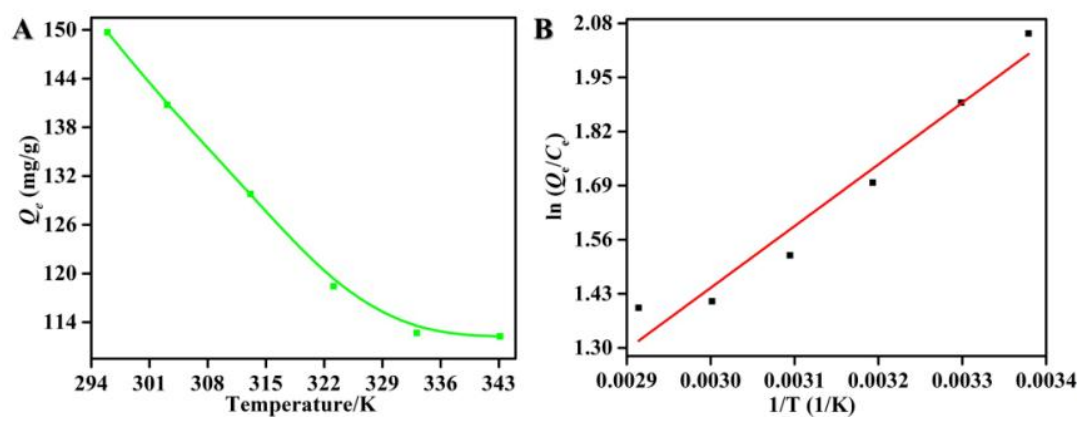

Fig. 7 (A) The effect of temperature on the adsorption of $\mathrm{MB}$ molecules by $\mathrm{SiO}_{2}-\mathrm{PDA}-\mathrm{PAA}$. Experimental conditions: $\mathrm{C}_{\mathrm{MB}}=50$ $\mathrm{mg} / \mathrm{L}$, solution $\mathrm{pH}=7.1$, contact time $=60 \mathrm{~min}$. (B) The Van't Hoff plot for the adsorption of the MB molecules onto $\mathrm{SiO}_{2}$-PDA-PAA.

Table 4 shows that $K \alpha$ decreased with increasing temperature. This indicated that the adsorption of $\mathrm{MB}_{\text {onto }} \mathrm{SiO}{ }_{2}-\mathrm{PDA}-\mathrm{PAA}$ nanocomposites was favored at $295 \mathrm{~K}$. The values of $\Delta G^{0}$ were found to be negative at different temperatures. This suggests that the adsorption was a spontaneous and favorable process. As temperature increased from 295 to $343 \mathrm{~K}$, the value of $\Delta G^{0}$ increased 
from -5.058 to $-3.984 \mathrm{~kJ} \cdot \mathrm{mol}^{-1}$. In addition, the negative value of $\Delta H^{0}$ confirmed that the adsorption process was exothermic. The negative value of $\Delta S^{0}$ suggests that the randomness decreased at the solid-liquid interface during adsorption of MB on the $\mathrm{SiO}_{2}$-PDA-PAA. Furthermore, the values of $\Delta H^{0}$ and $T \Delta S^{0}$ verified that the adsorption of MB was an enthalpy-controlled process. These results suggested that $\mathrm{SiO}_{2}$-PDA-PAA are very efficient adsorbents for the removal of cationic dyes at room temperature.

Table 4 Thermodynamic parameters for the adsorption of MB molecules onto $\mathrm{SiO}_{2}$-PDA-PAA nanocomposites.

\begin{tabular}{|c|c|c|c|c|}
\hline$T(\mathbf{K})$ & $K \alpha\left(\mathbf{L} \cdot \mathrm{g}^{-1}\right)$ & $\Delta G^{0}\left(\mathbf{k J} \cdot \mathrm{mol}^{-1}\right)$ & $\Delta H^{0}\left(\mathrm{~kJ} \cdot \mathrm{mol}^{-1}\right)$ & $\Delta S^{0}\left(\mathbf{k J} \cdot \mathrm{mol}^{-1} \cdot \mathbf{K}^{-1}\right)$ \\
\hline 295 & 7.811 & -5.058 & -12.33 & -0.02499 \\
\hline 303 & 6.613 & -4.761 & & \\
\hline 313 & 5.457 & -4.418 & & \\
\hline 323 & 4.582 & -4.089 & & \\
\hline 333 & 4.102 & -3.909 & & \\
\hline 343 & 4.041 & -3.984 & & \\
\hline
\end{tabular}

\section{Conclusions}

This study presented a facile method for surface modification of $\mathrm{SiO}_{2}$ nanoparticles with PAA via a combination of mussel-inspired chemistry and Michael addition reaction. The successful preparation of $\mathrm{SiO}_{2}$-PDA-PAA was confirmed with TEM, TGA, FT-IR and XPS. The adsorption performance of $\mathrm{SiO}_{2}$-PDA-PAA towards MB was studied at different conditions. Versus the adsorption capacity of the original $\mathrm{SiO}_{2}$ nanoparticles, the $\mathrm{SiO}_{2}$-PDA-PAA exhibited an obviously higher adsorption efficiency towards MB. The data show that the adsorption process of $\mathrm{MB}$ onto $\mathrm{SiO}_{2}$-PDA-PAA was $\mathrm{pH}$ dependent. The adsorption kinetics were pseudo-second-order and Langmuirian. The thermodynamic parameters demonstrated that the adsorption process for MB was feasible, spontaneous and exothermic. These results proved that the surface modification of $\mathrm{SiO}_{2}$ nanoparticles with PAA could obviously enhance their adsorption efficiency towards MB. Furthermore, this strategy could also be used to fabricate many other polymer nanocomposites for strong and universal adhesion of PDA. Therefore, this strategy provides a facile and efficient route to fabricate highly efficient adsorbents for environmental adsorption applications.

\section{Acknowledgments}

This research was supported by the National Science Foundation of China (Nos. 51363016, 21474057, 21564006, 21561022), and the National 973 Project (Nos. 2011CB935700). We thank LetPub (www.letpub.com) for its linguistic assistance during the preparation of this manuscript.

\section{References}

[1] Z. Li, J.C. Barnes, A. Bosoy, J.F. Stoddart, J.I. Zink, Mesoporous silica nanoparticles in biomedical applications, Chem. Soc. Rev., 41 (2012) 2590-2605.

[2] D. Tang, L. Zhang, Y. Zhang, Z.-A. Qiao, Y. Liu, Q. Huo, Mesoporous silica nanoparticles immobilized salicylaldimine cobalt complexes as high efficient catalysts for polymerization of 1, 3-butadiene, J Colloid Interf Sci, 369 (2012) 338 -343.

[3] E. Vega, C. Marzabadi, Y. Kazakevich, A.Y. Fadeev, Synthesis of chiral mesoporous silicas with oligo (saccharide) surfaces and their use in separation of stereoisomers, J Colloid Interf Sci, 359 (2011) 542-544.

[4] Y. Su, Y. He, H. Lu, L. Sai, Q. Li, W. Li, L. Wang, P. Shen, Q. Huang, C. Fan, The cytotoxicity of cadmium based, aqueous 
phase-Synthesized, quantum dots and its modulation by surface coating, Biomaterials, 30 (2009) 19-25.

[5] C. Heng, M. Liu, P. Wang, K. Wang, X. Zheng, D. Fan, J. Hui, X. Zhang, Y. Wei, Preparation of silica nanoparticles based multifunctional therapeutic systems via one-step mussel inspired modification, Chem. Eng. J., 296 (2016) $268-276$.

[6] Q. Qin, J. Ma, K. Liu, Adsorption of anionic dyes on ammonium-functionalized MCM-41, J Hazard Mater, 162 (2009) 133-139.

[7] N. Gargiulo, F. Pepe, D. Caputo, Modeling carbon dioxide adsorption on polyethylenimine-functionalized TUD-1 mesoporous silica, J Colloid Interf Sci, 367 (2012) 348-354.

[8] J. Li, X. Miao, Y. Hao, J. Zhao, X. Sun, L. Wang, Synthesis, amino-functionalization of mesoporous silica and its adsorption of Cr (VI), J Colloid Interf Sci, 318 (2008) 309-314.

[9] N. Guo, Y. Liang, S. Lan, L. Liu, G. Ji, S. Gan, H. Zou, X. Xu, Uniform $\mathrm{TiO}_{2}-\mathrm{SiO}_{2}$ hollow nanospheres: Synthesis, characterization and enhanced adsorption-photodegradation of azo dyes and phenol, Appl. Surf. Sci., 305 (2014) $562-574$.

[10] P. Wang, M. Cao, C. Wang, Y. Ao, J. Hou, J. Qian, Kinetics and thermodynamics of adsorption of methylene blue by a magnetic graphene-carbon nanotube composite, Appl. Surf. Sci., 290 (2014) 116-124.

[11] B. Yu, X. Zhang, J. Xie, R. Wu, X. Liu, H. Li, F. Chen, H. Yang, Z. Ming, S.-T. Yang, Magnetic graphene sponge for the removal of methylene blue, Appl. Surf. Sci., 351 (2015) 765-771.

[12] Y. Chen, E. Kang, K. Neoh, Y. Zhang, K. Tan, Oxidative graft polymerization of aniline on Si (100) surface modified by plasma polymerization of glycidyl methacrylate, Polym Eng Sci, 42 (2002) 1181-1196.

[13] S.R. Whaley, D. English, E.L. Hu, P.F. Barbara, A.M. Belcher, Selection of peptides with semiconductor binding specificity for directed nanocrystal assembly, Nature, 405 (2000) 665-668.

[14] M. Charbonnier, M. Alami, M. Romand, Plasma treatment process for palladium chemisorption onto polymers before electroless deposition, J Electrochem Soc, 143 (1996) 472-480.

[15] J.C. Love, L.A. Estroff, J.K. Kriebel, R.G. Nuzzo, G.M. Whitesides, Self-assembled monolayers of thiolates on metals as a form of nanotechnology, Chem Rev, 105 (2005) 1103-1170.

[16] J. Tian, H. Zhang, M. Liu, F. Deng, H. Huang, Q. Wan, Z. Li, K. Wang, X. He, X. Zhang, A bioinspired strategy for surface modification of silica nanoparticles, Appl. Surf. Sci., 357 (2015) 1996-2003.

[17] Y. Shi, M. Liu, K. Wang, H. Huang, Q. Wan, L. Tao, L. Fu, X. Zhang, Y. Wei, Direct surface PEGylation of nanodiamond via RAFT polymerization, Appl. Surf. Sci., 357 (2015) 2147-2153.

[18] J.H. Waite, T.J. Housley, M.L. Tanzer, Peptide repeats in a mussel glue protein: theme and variations, Biochemistry, 24 (1985) 5010-5014.

[19] H. Lee, S.M. Dellatore, W.M. Miller, P.B. Messersmith, Mussel-inspired surface chemistry for multifunctional coatings, Science, 318 (2007) 426-430.

[20] H. Lee, N.F. Scherer, P.B. Messersmith, Single-molecule mechanics of mussel adhesion, Proc Nat Acad Sci, 103 (2006) 12999-13003.

[21] Q. Wan, M. Liu, J. Tian, F. Deng, G. Zeng, Z. Li, K. Wang, Q. Zhang, X. Zhang, Y. Wei, Surface modification of carbon nanotubes by combination of mussel inspired chemistry and SET-LRP, Polym. Chem., 6 (2015) 1786-1792.

[22] Q. Wan, L. Mao, M. Liu, K. Wang, G. Zeng, D. Xu, H. Huang, X. Zhang, Y. Wei, Towards development of a versatile and efficient strategy for fabrication of GO based polymer nanocomposites, Polym. Chem., 6 (2015) 7211-7218.

[23] M. Liu, J. Ji, X. Zhang, X. Zhang, B. Yang, F. Deng, Z. Li, K. Wang, Y. Yang, Y. Wei, Self-polymerization of dopamine and polyethyleneimine: novel fluorescent organic nanoprobes for biological imaging applications, J. Mater. Chem. B, 3 (2015) 3476-3482.

[24] X. Zhang, S. Wang, L. Xu, Y. Ji, L. Feng, L. Tao, S. Li, Y. Wei, Biocompatible Polydopamine Fluoresecent Organic Nanoparticles: Facile Preparation and Cell Imaging, Nanoscale, 4 (2012) 5581-5584.

[25] B. Fei, B. Qian, Z. Yang, R. Wang, W. Liu, C. Mak, J.H. Xin, Coating carbon nanotubes by spontaneous oxidative polymerization of dopamine, Carbon, 46 (2008) 1795-1797.

[26] S.M. Kang, I. You, W.K. Cho, H.K. Shon, T.G. Lee, I.S. Choi, J.M. Karp, H. Lee, One - Step Modification of Superhydrophobic Surfaces by a Mussel - Inspired Polymer Coating, Angew Chem Int Edit, 49 (2010) 9401-9404.

[27] S.H. Yang, S.M. Kang, K.-B. Lee, T.D. Chung, H. Lee, I.S. Choi, Mussel-inspired encapsulation and functionalization of individual yeast cells, J Am Chem Soc, 133 (2011) 2795-2797.

[28] X. Zhang, J. Ji, X. Zhang, B. Yang, M. Liu, W. Liu, L. Tao, Y. Chen, Y. Wei, Mussel inspired modification of carbon 
nanotubes using RAFT derived stimuli-responsive polymers, RSC Adv, 3 (2013) 21817-21823.

[29] X. Zhang, M. Liu, X. Zhang, F. Deng, C. Zhou, J. Hui, W. Liu, Y. Wei, Interaction of tannic acid with carbon nanotubes: enhancement of dispersibility and biocompatibility, Toxicol Res, 4 (2015) 160-168.

[30] X. Zhang, M. Liu, Y. Zhang, B. Yang, Y. Ji, L. Feng, L. Tao, S. Li, Y. Wei, Combining mussel-inspired chemistry and the Michael addition reaction to disperse carbon nanotubes, RSC Adv, 2 (2012) 12153-12155.

[31] X. Zhang, G. Zeng, J. Tian, Q. Wan, Q. Huang, K. Wang, Q. Zhang, M. Liu, F. Deng, Y. Wei, PEGylation of carbon nanotubes via mussel inspired chemistry: Preparation, characterization and biocompatibility evaluation, Appl Surf Sci, 351 (2015) 425-432.

[32] Q. Wan, J. Tian, M. Liu, G. Zeng, Q. Huang, K. Wang, Q. Zhang, F. Deng, X. Zhang, Y. Wei, Surface modification of carbon nanotubes via combination of mussel inspired chemistry and chain transfer free radical polymerization, Appl. Surf. Sci., 346 (2015) $335-341$.

[33] X. Zhang, Q. Huang, M. Liu, J. Tian, G. Zeng, Z. Li, K. Wang, Q. Zhang, Q. Wan, F. Deng, Preparation of amine functionalized carbon nanotubes via a bioinspired strategy and their application in $\mathrm{Cu}^{2+}$ removal, Appl. Surf. Sci., 343 (2015) 19-27.

[34] Y. Shi, M. Liu, K. Wang, F. Deng, Q. Wan, Q. Huang, L. Fu, X. Zhang, Y. Wei, Bioinspired preparation of thermo-responsive graphene oxide nanocomposites in an aqueous solution, Polym. Chem., 6 (2015) 5876-5883.

[35] X. Zhang, J. Ji, X. Zhang, B. Yang, M. Liu, W. Liu, L. Tao, Y. Chen, Y. Wei, Mussel Inspired Modification of Carbon Nanotubes Using RAFT Derived Stimuli-responsive Polymers, RSC Adv., 3 (2013) 21817-21823.

[36] X. Zhang, M. Liu, Y. Zhang, B. Yang, Y. Ji, L. Feng, L. Tao, S. Li, Y. Wei, Combining Mussel-inspired Chemistry and the Michael Addition Reaction to Disperse Carbon Nanotubes, RSC Adv., 2 (2012) 12153-12155.

[37] Q. Wan, J. Tian, M. Liu, G. Zeng, Z. Li, K. Wang, Q. Zhang, F. Deng, X. Zhang, Y. Wei, Mussel inspired preparation of highly dispersible and biocompatible carbon nanotubes, RSC Adv., 5 (2015) 25329-25336.

[38] Y. Cao, X. Zhang, L. Tao, K. Li, Z. Xue, L. Feng, Y. Wei, Mussel-inspired Chemistry and Michael addition Reaction for Efficient Oil/water Separation, ACS Appl. Mater. Interf., 5 (2013) 4438-4442.

[39] L. Xu, N. Liu, Y. Cao, F. Lu, Y. Chen, X. Zhang, L. Feng, Y. Wei, Mercury Ion Responsive Wettability and Oil Water Separation, ACS Appl. Mater. Interf., 6 (2014) 13324-13329.

[40] Y. Liu, K. Ai, L. Lu, Polydopamine and its Derivative Materials: Synthesis and Promising Applications in Energy, Environmental, and Biomedical fields, Chem. Rev., (2014) DOI: 10.1021/cr400407a.

[41] W. Stöber, A. Fink, E. Bohn, Controlled growth of monodisperse silica spheres in the micron size range, J Colloid Interf Sci, 26 (1968) 62-69.

[42] L. Lu, R. Capek, A. Kornowski, N. Gaponik, A. Eychmüller, Selective fabrication of ordered bimetallic nanostructures with hierarchical porosity, Angew Chem Int Edit, 44 (2005) 5997-6001.

[43] W. Wang, B. Gu, L. Liang, W. Hamilton, Fabrication of two-and three-dimensional silica nanocolloidal particle arrays, J Phys Chem B, 107 (2003) 3400-3404.

[44] T. Zhang, Q. Zhang, J. Ge, J. Goebl, M. Sun, Y. Yan, Y.-s. Liu, C. Chang, J. Guo, Y. Yin, A self-templated route to hollow silica microspheres, J Phys Chem C, 113 (2009) 3168-3175.

[45] X. Zhang, Q. Huang, M. Liu, J. Tian, G. Zeng, Z. Li, K. Wang, Q. Zhang, Q. Wan, F. Deng, Preparation of amine functionalized carbon nanotubes via a bioinspired strategy and their application in $\mathrm{Cu} 2+$ removal, Appl Surf Sci, 343 (2015) 19-27.

[46] E. Demirbas, M. Kobya, E. Senturk, T. Ozkan, Adsorption kinetics for the removal of chromium (VI) from aqueous solutions on the activated carbons prepared from agricultural wastes, Water Sa, 30 (2004) p. 533-539.

[47] I.A. Darwish, D.A. Blake, Development and validation of a one-step immunoassay for determination of cadmium in human serum, Anal Chem, 74 (2002) 52-58.

[48] P. Sun, C. Hui, R.A. Khan, J. Du, Q. Zhang, Y.-H. Zhao, Efficient removal of crystal violet using Fe3O4-coated biochar: the role of the Fe3O4 nanoparticles and modeling study their adsorption behavior, Sci Rep-UK, 5 (2015).

[49] M. Brdar, M. Šćiban, A. Takači, T. Došenović, Comparison of two and three parameters adsorption isotherm for Cr (VI) onto Kraft lignin, Chem Eng J, 183 (2012) 108-111.

[50] G. Annadurai, L.Y. Ling, J.-F. Lee, Adsorption of reactive dye from an aqueous solution by chitosan: isotherm, kinetic and thermodynamic analysis, J Hazard Mater, 152 (2008) 337-346. 
[51] M. Rauf, S. Bukallah, F. Hamour, A. Nasir, Adsorption of dyes from aqueous solutions onto sand and their kinetic behavior, Chem Eng J, 137 (2008) 238-243.

[52] W. Konicki, I. Pełech, E. Mijowska, I. Jasińska, Adsorption of anionic dye Direct Red 23 onto magnetic multi-walled carbon nanotubes-Fe3C nanocomposite: Kinetics, equilibrium and thermodynamics, Chem Eng J, 210 (2012) 87-95.

[53] L. Ai, J. Jiang, Removal of methylene blue from aqueous solution with self-assembled cylindrical graphene-carbon nanotube hybrid, Chem Eng J, 192 (2012) 156-163.

[54] L. Ai, C. Zhang, Z. Chen, Removal of methylene blue from aqueous solution by a solvothermal-synthesized graphene/magnetite composite, J Hazard Mater, 192 (2011) 1515-1524. 